\title{
Student centered curricular elements are associated with a healthier educational environment and lower depressive symptoms in medical students
}

Eiad Abdelmohsen AlFaris, Naghma Naeem*, Farhana Irfan, Riaz Qureshi and Cees van der Vleuten

\begin{abstract}
Background: Any curriculum change is essentially an environmental change; therefore there is a need to assess the impact of any change in the curriculum on the students' perception of the Educational Environment (EE) and psychological well-being. The objectives of the current study are to (i) compare the EE perceptions of medical students studying in a System Based Curriculum (SBC) with those studying in a traditional curriculum (ii) compare the rate of depressive symptoms among the same students studying in both types of curricula (iii) determine whether there is a difference in the EE perception and depressive symptoms based on gender and year of study.

Methods: A cross sectional survey was conducted in a Saudi Medical School from 2007-2011, a period in which the school transitioned from a traditional to a SBC. A bilingual version of the Dundee Ready Educational Environment Measure (DREEM) inventory was used for measuring the EE; the Beck Depression Inventory (BDI II) was used for screening of depressive symptoms. A separate demographic questionnaire was also used. Mean scores and percentages were calculated. Continuous variables were summarized as means and standard deviation. For comparison of means, the effect size and student $t$ test (with significance level of $<0.05$ ) were used. The percentages of the categorical data were compared using chi square test.

Results: The mean total DREEM score of positive perception of the EE in the SBC students was significantly higher (better) than the traditional curriculum students $(p<0.01)$ with an effect size of 0.472 . The mean total score on the BDI-II inventory for depressive symptoms was higher (sicker) 21.3 among the female traditional curriculum students than 16.7 among the male traditional curriculum students and the difference was statistically significant $(p=0.001)$. The BDI score of the female SBC students (14.7) was significantly lower (healthier) than the female traditional curriculum students (21.3). No similar change was noted for the male students.
\end{abstract}

Conclusion: The current study adds to the advantages of the SBC indicating not only healthier EE for both genders but also healthier emotional well-being for female students only.

Keywords: Curriculum, Educational environment, Depressive symptoms, Medical students

\footnotetext{
* Correspondence: naghma.naeem@gmail.com

King Saud University Chair for Medical Education Research and

Development, King Saud University, Riyadh, Kingdom of Saudi Arabia
} 


\section{Background}

The Educational Environment (EE) refers to the social, psychological and pedagogical contexts in which learning occurs and which affect student achievements, attitudes and wellbeing [1-3]. It plays a significant role in relation to the student's behavior, academic development and wellbeing. The literature suggests that although the concept is rather intangible, the effects of the EE are substantial, real and influential $[2,4]$.

Traditionally, curricula at most medical colleges were non-integrated, teacher-centered, information gathering, opportunistic, discipline and hospital-based with a set of mandated courses [5]. However, with changes in clinical practice and societal demands, there is a move towards more integrated curricula. The new curricula are integrated around either systems or clinical presentations [6]. The systems-based curricula (SBC) are integrated around organ systems with inclusion of early clinical and practical skills training and small-group learning [6].

Medical education is perceived as being stressful and can have a negative impact on cognitive functioning and learning [7]. Rates of depression and suicide are higher among medical students than other university studies' students $[8,9]$. The rates remain elevated even when these students become physicians.

Research studies using a variety of instruments have reported a range of figures for prevalence of depressive symptoms among medical students - 43.89\% [10], 25\% [11], 21.7\% [12], 71.25\% [13], 12-30\% [14], 18.6\% [15]. On the other hand, among the general population, the rate of $3 \%$ to $4 \%$ was observed [16,17].

A study among Saudi medical students found a 57\% prevalence of stress, with $19.6 \%$ of them having severe stress [18]. The presence and severity of depressive symptoms had a statistically significant association with early academic years $(\mathrm{p}<0.000)$ and female gender $(\mathrm{p}<$ 0.002) [19]. A systematic review concluded that studying medicine is a time of significant psychological distress [20]. One of the factors found to be associated with higher stress and psychological illnesses was adjustment to the medical school environment [21]. Although the EE and the depressive symptoms have been studied separately in traditional and system based curricula; none of these studies have addressed both the variables together. The current study was carried out in a school that moved from a traditional curriculum to a system-based one providing an ideal opportunity to study the two variables together and to compare the two systems across time before and after the change.

The objectives of the current study are to (i) compare the EE perception of medical students studying in a $\mathrm{SBC}$ with those studying in a traditional curriculum (ii) compare the rate of depressive symptoms among the students studying in the two curricula (iii) determine whether there is a difference in perception of EE and depressive symptoms based on gender and year of study.

\section{Method}

\section{Study setting and the curriculum}

The current study was conducted in the medical school of King Saud University (KSU) which was established in 1973. The KSU curriculum until the year 2007/2008 was traditional, as defined by the General Medical Council (1993) and it was changed to SBC starting in the year 2008/2009. Like other Saudi medical schools, KSU operates on a single-gender basis (teaches the two genders separately). The intake of male students was more than double that of female students till the year 2007. After that, almost equal intake of male and female students was adopted.

\section{The traditional curriculum versus the SBC}

The curriculum, before the change, was non-integrated, discipline based and teacher centered using didactic lectures as the main teaching strategy. The grading system was largely based on summative assessment system i.e. the grade $\mathrm{A}+$ being the highest, followed by $\mathrm{B}, \mathrm{C}$, and $\mathrm{D}$ for pass and $\mathrm{F}$ for fail. The new $\mathrm{SBC}$ is integrated horizontally with a move towards vertical integration. The first two years of the new curriculum consist of ten organ systems taught using problem-based learning (PBL) strategy. A student support system was established. The number of elective courses was increased. Students were introduced to ambulatory care early in the program and the duration of ambulatory care training was increased. The teaching strategies include small-group discussions, interactive lectures and self-directed learning. Teaching resources include study guides, an electronic learning management system, skills lab and virtual patients. The assessment is balanced between formative and summative assessment and the grading system is similar to the traditional curriculum grading system mentioned earlier.

\section{The outcome variables \\ Educational environment}

The DREEM inventory was used to measure the perception of the EE. The DREEM was initially reported to be valid and culture free [22-25]. Although the minimal sources of evidence reduced its validity; it is still the mostly widely used questionnaire for the undergraduate curriculum [26]. It comprises of 50 items relating to a range of topics directly relevant to the educational climate [16] and is divided into five subscales (Additional file 1). The items of the inventory were scored as suggested by the authors of the inventory as follows: 4 for Strongly Agree (SA), 3 for Agree (A), 2 for Uncertain (U), 1 for Disagree (D) and 0 for Strongly Disagree (SD) [22]. The approximate guide to interpreting the DREEM results is summarized as follows: 
A mean overall total score of $0-50$ is interpreted as very poor, 51-100 (plenty of problems), 101-150 (more positive than negative) and 151-200 (excellent). The higher the score of an item, the more positive is the students' perception of the environment. The inventory has a maximum score of 200, which indicates the ideal EE.

\section{Depressive symptoms}

The BDI-II Inventory was used to measure the depressive symptoms. It was selected because of its specificity at detecting depressive symptoms among college students $[27,28]$. The BDI-II is a 21 item, self-report instrument, which measures the severity of depression in both adults and adolescents aged 13 years and older [28]. The BDI-II version was developed for the assessment of symptoms corresponding to the criteria for diagnosing depressive disorders listed in the American Psychiatric Association's Diagnostic and Statistical Manual of Mental Disorders (DSM-IV, 1994). The instrument is rated on a four point scale ranging from 0-3. The scores from all items are added to get the total score for an individual. The higher the score, the more depressed the student is. A score of $0-13$ is considered minimal depression, $14-19=$ mild, 20-28 = moderate and 29-63 severe depression [28].

\section{Participants}

The study participants included two cohorts of students: a) all $1^{\text {st }}$ and $2^{\text {nd }}$ year students enrolled in the College of Medicine, KSU during the year 2007/ 2008 studying in the traditional curriculum b) all $1^{\text {st }}$ and $2^{\text {nd }}$ year students enrolled in the College of Medicine, KSU during the year 2010/ 2011 studying in the SBC. No sampling method was used as the whole population was invited to participate.

\section{Data collection}

The three questionnaires (including a separate demographic questionnaire) were administered to all the study participants during the middle of the second semester, more than two weeks before the mid-term exam. The instruments were administered at a time when the students were sufficiently acquainted with the school environment and informed verbal consent was taken with optional participation. An attached covering letter to the questionnaires included the names of the researchers and an assurance of confidentiality. It was mentioned in the covering letter that the purpose of the study was to assess the EE as the DREEM noticeably investigates the EE no further details of the study were mentioned, such as the association of the depressive symptoms with the EE to avoid bias.

\section{Ethics statement}

The current study was approved by the Institutional Review Board of King Saud University -College of Medicine (reference no. 11/3106/IRB) dated 22/06/2011.

\section{Analysis}

In order to address the first and third objectives, the mean total score of the DREEM and the mean score of the five domains of the inventory were calculated and compared for curricula cohorts, year of study and gender. In order to address the second and third objective, comparison of the mean BDI score was made between the two curricula cohorts, across the two academic years and the two genders. Descriptive statistics (mean, standard deviation and proportion) were used to describe the quantitative variables. Continuous variables were summarized as means and 95\% confidence intervals (CI). The effect size and student $t$ test were used for comparison. The chi square test was used for comparison between categorical variables. A p-value of $<0.05$ was considered as statistically significant. Data was analyzed using SPSS version 16.0.

\section{Results}

\section{Demographics}

The number of students who participated in the EE study from the SBC cohort was 249 and from the traditional curriculum were 458. The participants' age ranged between 18 and 21 years. While a larger number of male than female students participated in the traditional curriculum, they were almost equal in the SBC (Table 1). The response rate of the DREEM inventory in both cohorts of students and the BDI-II for the SBC students was almost complete. On the other hand, only $65 \%$ of the students in the traditional curriculum had completely filled out the BDI-II.

\section{DREEM scores in traditional curriculum versus SBC}

The mean DREEM total score for the SBC students $(118.5 / 200)$ was significantly higher than that of the traditional curriculum (94.6/200). The effect size (-0.47) was medium and of moderate practical importance, according to Cohen's operational definition [29] (Table 2). The scores in all the five domains of the DREEM were higher in the SBC. First year students perceived the environment (mean total DREEM) better than second year in both curricula (Table 2).

This was noted for both sexes in the traditional curriculum. There was no significant decline in the DREEM scores among the SBC students. There was a higher mean total DREEM score for the female students compared to their male counterparts for both years and in both cohorts (Table 3). 
Table 1 The demographic characteristics of the two groups of students

\begin{tabular}{lllll}
\hline & & Traditional curriculum number (\%) & Systemic based curriculum number (\%) & Total number \\
\hline Gender & Male & $330(73.5)$ & $127(51.0)$ & 457 \\
& Female & $119(26.5)$ & $122(49.0)$ & 241 \\
Total & & 449 & 249 & 698 \\
Year of study & First & $239(52.2)$ & $122(49.0)$ & 361 \\
& Second & $219(47.8)$ & $127(51.0)$ & 346 \\
Total & & 458 & 249 & 707 \\
\hline
\end{tabular}

\section{BDI II scores in traditional versus SBC}

The mean BDI-II total score for depressive symptoms was higher (sicker) for the students of the traditional curriculum (18.0) compared to the SBC (15.6) for the two years (Table 2), giving a small effect size (negligible practical importance) [29]. The prevalence of severe depressive symptoms was greater among the first year students compared with their second year counterparts for both curricula (Table 4). A statistically significant association $(\mathrm{p}=0.001)$ was found between the student gender and the severity of depressive symptoms among the traditional curriculum students; being more severe among the female students (Table 4). The gender trend for more severe symptoms of depression was reversed among the students of SBC, though it did not reach a statistically significant association $(\mathrm{p}=0.271)$.

\section{Discussion}

The response rate of the DREEM inventory for both cohorts of students and the BDI II for the SBC students was almost complete, which was reassuring. However, only two third of the students in the traditional curriculum had completely filled out the BDI-II. It could be that the students when filling out the three questionnaires were exhausted when they reached the last one (BDI-II).

The mean total DREEM score of the cohort of students from the SBC in the current study $(118.5 / 200)$ is in the middle of the results of studies conducted among medical students worldwide [30-32]. The SBC students perceived the EE significantly better than the traditional curriculum students $(95 / 200)$, which is consistent with the findings of other reports $[4,33,34]$. The possible reasons for this improvement could be that the instructional methods were more relaxed, practical and enjoyable. The introduction of a study guide with the SBC might have contributed to this improvement, as it enabled students to manage their time and learning tasks well in order to become self-regulated learners [31].

It is noteworthy that the scores of the first year students of the traditional curriculum (105/200) were higher than the scores of second year students (92/200). No similar decline was observed with the SBC students. The decline in the mean EE scores was observed for both genders in the traditional curriculum. The possible explanation is that the students studying in the traditional curriculum may have entered the school with optimism but were disappointed by the curriculum overload and the competitive environment. This may also be attributed to the fact that students have to face the limits of their cognitive capacities to achieve the required knowledge and also to adjust to significant changes in their daily routine $[8,35,36]$. This decline in the scores of all the EE domains in the second year, is consistent with that reported by other medical schools $[37,38]$.

The significantly higher mean total DREEM scores for female students in both the traditional (99/200), and the system based $(123 / 200)$ curricula as compared to their male counterparts (93/200) and (113/200) respectively, suggests that the female students were relatively more satisfied with learning, teaching and the school atmosphere, which is consistent with the reports of other studies $[30,39,40]$.

Reasons for depression among medical students are multifactorial and include adjustment to large volume of information, competition and concern over failure in their studies. In addition to the genetic and other environmental factors that occur regardless of the educational stress $[19,41]$. Nurturing students' personal development, psychological and physical health is very

Table 2 A comparison of total DREEM scores and BDI scores by year of study

\begin{tabular}{|c|c|c|c|c|c|c|c|c|c|c|}
\hline & \multicolumn{5}{|c|}{ DREEM } & \multicolumn{5}{|c|}{ BDI II } \\
\hline & \multicolumn{5}{|c|}{ Mean total score } & \multicolumn{5}{|c|}{ Mean total score } \\
\hline & Traditional & System based & T value & $P$ value & Effect Size & Traditional & System based & T value & $P$ value & Effect size \\
\hline $1^{\text {st }}$ year & 104.54 & 120.97 & 8.5 & $<0.0001$ & 0.472 & $18.79(10.8)$ & $15.88(9.4)$ & 2.4 & 0.017 & 0.123 \\
\hline 2nd year & 91.65 & 118.38 & 12.3 & $<0.0001$ & & $16.81(9.4)$ & $15.37(8.3)$ & 1.27 & 0.20 & \\
\hline Total & $94.6(21.0)$ & $118.5(23.5)$ & 14.21 & $<0.01$ & & 18.0 (10.3) & $15.6(8.9)$ & 2.91 & 0.004 & \\
\hline
\end{tabular}


Table 3 A comparison of total DREEM scores by sex and year of study

\begin{tabular}{|c|c|c|c|c|c|c|c|c|c|c|c|}
\hline \multirow[t]{2}{*}{ Curriculum type } & \multirow[t]{2}{*}{ Year } & \multicolumn{3}{|c|}{ Male } & \multicolumn{3}{|c|}{ Female } & \multicolumn{3}{|c|}{ Total } & \multirow[t]{2}{*}{ P value } \\
\hline & & $\mathrm{N}$ & Mean & SD & $\mathrm{N}$ & Mean & SD & $\mathrm{N}$ & Mean & SD & \\
\hline \multirow[t]{3}{*}{ Traditional } & First & 166 & 99.51 & 19.67 & 73 & 103.38 & 17.37 & 239 & 100.69 & 19.04 & NS \\
\hline & Second & 168 & 86.10 & 21.62 & 51 & 93.86 & 18.44 & 219 & 87.90 & 21.14 & $P<0.05$ \\
\hline & Total & 334 & 92.76 & 21.71 & 124 & 99.47 & 18.36 & 458 & 94.58 & 21.04 & $P<0.05$ \\
\hline \multirow[t]{3}{*}{ SBC } & First & 57 & 114.89 & 22.31 & 73 & 123.73 & 23.22 & 130 & 119.85 & 23.16 & $\mathrm{P}<0.05$ \\
\hline & Second & 79 & 112.38 & 22.23 & 65 & 123.09 & 24.63 & 144 & 117.22 & 23.87 & $\mathrm{P}<0.05$ \\
\hline & Total & 136 & 113.43 & 22.22 & 138 & 123.43 & 23.81 & 274 & 118.47 & 23.53 & $\mathrm{P}<0.05$ \\
\hline
\end{tabular}

*LEs improved in the Abdul Jabbar. cribed by Beck*.

*Results are based on two-sided tests assuming equal variances with significance level 0.05 .

important and similar in importance to acquiring the knowledge and skills needed to be future physicians [42].

For SBC female students, the mean total BDI score was significantly lower than for traditional female students, but this trend was not observed with the male students. What is there about female students who seem to have benefited psychologically by the change to the SBC? There must be a phenomenon related to the female students that indicates a positive impact of curriculum change on their mental health and wellbeing. It appears that the female students prefer PBL style of learning and had better satisfaction with the EE compared with their male counterparts. As has been mentioned earlier that the curriculum at KSU operates on single gender basis and therefore, another plausible explanation might be that the female student's teaching in the traditional curriculum may have been inferior to that of their male counterparts. It is possible that the change in the teaching strategy in the SBC e. g. small group teaching, less curricular load and smaller class size had a greater positive impact on their psychological wellbeing and perception of EE. These plausible reasons need to be confirmed by a qualitative study and deserve further exploration [42].
Several studies have reported the rate of depressive symptoms among medical students, but have not explored its relationship with their perceptions of the EE.

The lower rate and severity of depressive symptoms among second year students compared with the first year students in the current study contradicts the findings of a Turkish study which reported a significant rise in the scores on the BDI-II among medical students between the first and second years [41]. Similarly another study among Chinese medical students found doubling of depression in medical students between the beginning and the end of the first year [43].

It is interesting to note in the current study that while the first year students were more satisfied with the EE, they had a slightly higher rate of depressive symptoms than the second year students although the difference was not significant. This phenomenon might be explained by the "transactional theory of stress and coping" [44] which explains the stressed person -environment relationship.

The finding of a higher rate of depressive symptoms among female students in the traditional curriculum is consistent with findings of other studies [10,21,45-48]. On the other hand, the finding of a lower rate of depressive

Table 4 Demographic characteristics versus BDI II scores and the statistical association (Traditional Curriculum and System Based Curricula)

\begin{tabular}{|c|c|c|c|c|c|c|c|c|c|c|}
\hline & & & Total No. & $\begin{array}{l}\text { Minimal } \\
\mathrm{n}(\%)\end{array}$ & $\begin{array}{l}\text { Mild } \\
\text { n (\%) }\end{array}$ & $\begin{array}{l}\text { Moderate } \\
\text { n (\%) }\end{array}$ & $\begin{array}{l}\text { Severe } \\
\text { n (\%) }\end{array}$ & Mean total score (SD) & Chi square & $P$ value \\
\hline \multirow[t]{5}{*}{ Traditional } & Academic year & 1st & 176 & $63(35.8)$ & $42(23.9)$ & $40(22.7)$ & $31(17.6)$ & $18.79(S D=10.83)$ & 2.626 & .453 \\
\hline & & 2nd & 118 & $45(38.1)$ & $33(28.0)$ & $27(22.9)$ & $13(11.0)$ & $16.81(\mathrm{SD}=9.43)$ & & \\
\hline & & Total & 294 & $108(36.7)$ & $75(25.5)$ & $67(22.7)$ & $44(14.9)$ & $18.0(S D=10.3)$ & & \\
\hline & Gender & Male & 213 & $91(42.7)$ & $55(25.8)$ & $38(17.8)$ & $29(13.6)$ & $16.74(S D=10.16)$ & 16.827 & .001 \\
\hline & & Female & 81 & $17(21.0)$ & $20(24.7)$ & $29(35.8)$ & $15(18.5)$ & $21.31(S D=10.07)$ & & \\
\hline \multirow[t]{5}{*}{ SBC } & Academic year & 1st & 122 & $59(48.4)$ & $30(24.6)$ & $24(19.7)$ & $9(7.4)$ & $15.88(\mathrm{SD}=9.43)$ & .833 & .842 \\
\hline & & 2nd & 127 & $59(46.5)$ & $31(24.4)$ & 30 (23.6) & $7(5.5)$ & $15.37(\mathrm{SD}=8.36)$ & & \\
\hline & & Total & 249 & $118(47.4)$ & $61(24.4)$ & $54(21.6)$ & $16(6.4)$ & $15.6(\mathrm{SD}=8.9)$ & & \\
\hline & Gender & Male & 127 & $61(48.0)$ & $26(20.5)$ & $29(22.8)$ & $11(8.7)$ & $16.48(S D=10.05)$ & 3.911 & .271 \\
\hline & & Female & 122 & $57(46.7)$ & $35(28.7)$ & $25(20.5)$ & $5(4.1)$ & $14.72(\mathrm{SD}=7.43)$ & & \\
\hline
\end{tabular}


symptoms among female students in the SBC (though statistically not significant) contradicts the finding of other studies that found more female than male medical students becoming depressed during the first two years of schooling [10,21,47]. However, a recent study from Malaysia reports similar findings [48]. Women, in general ,are known to have a higher lifetime risk of depression and anxiety than men [20]. A multi-country study of undergraduate students reported a higher rate of depression among males than females in Saudi Arabia [49]. This study also reported that in some other regional countries females tended to have higher rates of depression than males namely Iraq, Syria, Egypt, Pakistan, Algeria, Oman, Qatar, Morocco, and Kuwait [49]. On the other hand, no significant gender differences in depression were observed in Lebanon, Tunisia, Palestine, United Arab Emirates, Yemen, Jordan, and Sudan [49].

\section{Limitations and strengths}

The current study used comparable data for the system based and the traditional curricula. Since, few studies have addressed the impact of student centered teaching on student psychological wellbeing; the results of this study can be used as a proxy indicator of student wellbeing and can be accepted as a baseline for further investigation. This study has some limitations including the use of self-administered inventories rather than structured interviews for exploration and clinical diagnoses. Furthermore, it was conducted in only one school. The sample size was relatively large, and the response rate was high for all the study groups, however, there was a relatively low response rate for the BDI-II inventory by students of the traditional curriculum.

\section{Conclusion}

The SBC students perceived the EE more positively than their traditional curriculum counterparts. Depressive symptoms were found to be significantly less and milder among the female SBC students compared with their male counterparts in the traditional curriculum. The current study adds to the advantages of the SBC in terms of healthier EE for both genders but an improved emotional well-being for female students only.

\section{Additional file}

\section{Additional file 1: Guide for interpretation of DREEM scores.}

\section{Competing interests}

The authors declare that they have no competing interests.

\section{Authors' contributions}

EF conceived of the study and participated in its design, coordination and data collection and was the main author of the manuscript. NN contributed to writing of first draft and revision of the subsequent drafts of the manuscript and analyses of results. FI was involved in writing of the manuscript and analyses of data. RQ was involved in writing of the manuscript and language editing. CV contributed to critical revision of manuscript. All authors read and approved the final manuscript.

\section{Acknowledgement}

This research is supported by the College of Medicine Research Centre, King Saud University.

Received: 28 August 2013 Accepted: 9 September 2014

Published: 17 September 2014

\section{References}

1. Fraser BJ: The birth of a new journal: Editor's introduction. Learn Environ Res 1998, 1(1):1-5.

2. Genn J: AMEE Medical Education Guide No. 23 (Part 1): Curriculum, environment, climate, quality and change in medical education-a unifying perspective. Med Teach 2001, 23(4):337-344.

3. Kember D, Leung DYP: Development of a questionnaire for assessing students' perceptions of the teaching and learning environment and its use in quality assurance. Learning Environ Res 2009, 12(1):15-29.

4. Soemantri D, Herrera C, Riquelme A: Measuring the educational environment in health professions studies: A systematic review. Med Teach 2010, 32(12):947-952.

5. Harden R, Sowden S, Dunn W: Educational strategies in curriculum development: the SPICES model. Med Educ 2009, 18(4):284-297.

6. Custers EJFM, Cate OTJT: Medical students' attitudes towards and perception of the basic sciences: a comparison between students in the old and the new curriculum at the University Medical Center Utrecht, The Netherlands. Med Educ 2002, 36(12):1142-1150.

7. Saipanish R: Stress among medical students in a Thai medical school. Med Teach 2003, 25(5):502-506.

8. Rosal MC, Ockene IS, Ockene JK, Barrett SV, Ma Y, Hebert JR: A longitudinal study of students' depression at one medical school. Acad Med 1997, 72(6):542-546.

9. Rosenthal JM, Okie S: White coat, mood indigo-depression in medical school. New England J Med 2005, 353(11):1085-1088.

10. Jadoon NA, Yaqoob R, Raza A, Shehzad MA, Zeshan SC: Anxiety and depression among medical students: a cross-sectional study. J Pakistan Med Asso 2010, 60:699-702.

11. Ghodasara SL, Davidson MA, Reich MS, Savoie CV, Rodgers SM: Assessing student mental health at the Vanderbilt University School of Medicine. Acad Med 2011, 86(1):116-121.

12. Yusoff MSB, Rahim AFA, Yaacob MJ: The prevalence of final year medical students with depressive symptoms and its contributing factors. Int Med J 2011, 18(4):305-309.

13. Kumar GS, Jain A, Hegde S: Prevalence of depression and its associated factors using Beck Depression Inventory among students of a medical college in Karnataka. Indian J Psychiatry 2012, 54:223-226.

14. Yusoff MS, Abdul Rahim AF, Baba AA, Ismail SB, Mat Pa MN, Esa AR: The impact of medical education on psychological health of students: $A$ cohort study. Psychol Health Med 2013, 18:420-430.

15. Bassols AM, Okabayashi LS, da Silva AB, Carneiro BB, Feijo F, Guimaraes GC, Cortes GN, Rohde LA, Eizirik CL: First-and last-year medical students: is there a difference in the prevalence and intensity of anxiety and depressive symptoms? Rev Bras Psiquiatr doi:10.1590/1516-4446-2013-1183.

16. Barrett J, Hurst MW, DiScala C, Rose RM: Prevalence of depression over a 12-month period in a non patient population. Arch Gen Psychiatry 1978, 35(6):741.

17. Clark DC, Zeldow PB: Vicissitudes of depressed mood during four years of medical school. JAMA 1988, 260(17):2521-2528.

18. Abdulghani HM: Stress and depression among medical students: A cross sectional study at a medical college in Saudi Arabia. Pakistan J Med Sci 2008, 24(1):12.

19. Al-Faris E, Irfan F, Van Der Vleuten C, Naeem N, Alsalem A, Alamiri N, Alraiyes T, Alfowzan M, Alabdulsalam A, Ababtain A, Aljabab S, Bukhari M, Alsinaidi O, Alofaisan Y: The prevalence and correlates of depressive symptoms from an Arabian setting: A wake up call. Med Teach 2012, 34(s1):32-36. 
20. Dyrbye LN, Thomas MR, Shanafelt TD: Systematic review of depression, anxiety, and other indicators of psychological distress among US and Canadian medical students. Acad Med 2006, 81(4):354-373.

21. Goebert D, Thompson D, Takeshita J, Beach C, Bryson P, Ephgrave K, Kent A Kunkel M, Schechter J, Tate J: Depressive symptoms in medical students and residents: a multi-school study. Acad Med 2009, 84(2):236-241.

22. McAleer S, Roff S: A practical guide to using the Dundee Ready Education Environment Measure (DREEM) 2003.www.gppro.co.uk/swacpo/document/ dreems2.doc.

23. Roff S: The Dundee Ready Educational Environment Measure (DREEM)-a generic instrument for measuring students' perceptions of undergraduate health professions curricula. Med Teach 2005, 27(4):322-325

24. Roff S, McAleer S, Harden RM, Al-Qahtani M, Ahmed AU, Deza H, Groenen G, Primparyon P: Development and validation of the Dundee ready education environment measure (DREEM). Med Teach 1997, 19(4):295-299.

25. Roff S, McAleer S, Ifere O, Bhattacharya S: A global diagnostic tool for measuring educational environment: comparing Nigeria and Nepal. Med Teach 2001, 23(4):378-382

26. Isba R, Boor K: Creating a learning environment. In Medical Education. Theory and Practice. Churchill Livingstone: Dorman, Scherpbier and Spencer; 2011:99-114.

27. Beck AT, Steer RA, Carbin MG: Psychometric properties of the Beck Depression Inventory: Twenty-five years of evaluation. Clin Psychol Rev 1988, 8(1):77-100.

28. Beck AT, Steer RA, Brown GK: Manual for the Beck depression inventory-ll. San Antonio, TX: Psychological Corporation; 1996.

29. Hojat MR, XU2 G: A visitor's guide to effect sizes statistical significance versus practical (clinical) importance of research findings. Adv Health Sci Educ 2004, 9:241-249.

30. Bassaw B, Roff S, McAleer S, Roopnarinesingh S, De Lisle J, Teelucksingh S, Gopaul S: Students' perspectives on the educational environment, Faculty of Medical Sciences, Trinidad. Med Teach 2003, 25(5):522-526.

31. Varma R, Tiyagi E, Gupta JK: Determining the quality of educational climate across multiple undergraduate teaching sites using the DREEM inventory. BMC Med Educ 2005, 5(1):8.

32. Al Faris EA, Naeem N, McAleer $S$, Qureshi R, Van der Vleuten C, Irfan F, Jamal A: Why a teacher centered medical school curriculum may result in a poor educational environment. J Contemp Med Edu 2013, 2(2):85-90. doi:10.5455/jcme.20140620013233.

33. Arzuman H, Yusoff MSB, Chit SP: Big Sib Students' Perceptions of the Educational Environment at the School of Medical Sciences, Universiti Sains Malaysia, using Dundee Ready Educational Environment Measure (DREEM) Inventory. Malaysian J Med sSci 2010, 17(3):40.

34. Mayya S, Roff S: Students' perceptions of educational environment: a comparison of academic achievers and under-achievers at Kasturba Medical College, India. Education for Health, Abingdon: Carfax Publishing Limited; 2004:280-291.

35. Schwartz PL, Loten EG: Effect of year in school on medical students' perceptions evaluated with the Cognitive Behavior Survey, Attitudes Toward Social Issues in Medicine Survey, and Learning Environment Questionnaire. Teach Learn Med 2004, 16(4):333-344.

36. Shapiro SL, Shapiro DE, Schwartz GER: Stress management in medical education: a review of the literature. Acad Med 2000, 75(7):748-759.

37. Khogali SEO, Laidlaw JM, Harden RM: Study guides: a study of different formats. Med Teach 2006, 28(4):375-377.

38. Dunne F, McAleer S, Roff S: Assessment of the undergraduate medical education environment in a large UK medical school. Health Educ J 2006, 65(2):149-158.

39. Abraham R, Ramnarayan K, Vinod P, Torke S: Students' perceptions of learning environment in an Indian medical school. BMC Med Educ 2008, 8(1):20.

40. Lokuhetty MDS, Warnakulasuriya SP, Perera RIR, Silva HTRD, Wijesinghe HD: Students' perception of the educational environment in a Medical Faculty with an innovative curriculum in Sri Lanka. South-East Asian J Med Educ 2011, 4(1):9-16.

41. Aktekin M, Karaman T, Senol YY, Erdem S, Erengin H, Akaydin M: Anxiety, depression and stressful life events among medical students: a prospective study in Antalya. Turkey Med Educ 2001, 35(1):12-17.

42. Snadden D: Editorial: Student health and abuse: what is going on out there? Med Teach 2003, 25(5):461-462.
43. Seabrook MA: Clinical students' initial reports of the educational climate in a single medical school. Med Educ 2004, 38(6):659-669.

44. Folkman S, Lazarus RS: If it changes it must be a process: Study of emotion and coping during three stages of a college examination. J Pers Soc Psychol 1985, 48(1):150.

45. Amr M, El Gilany AH, El-Hawary A: Does gender predict medical students stress in Mansoura, Egypt? Med Educ Online 2008, 13:12.

46. Baldassin S, Alves T, De Andrade A, Martins LN: The characteristics of depressive symptoms in medical students during medical education and training: a cross-sectional study. BMC Med Educ 2008, 8(1):60.

47. Schwenk TL, Davis L, Wimsatt LA: Depression, stigma, and suicidal ideation in medical students. JAMA 2010, 304(11):1181-1190.

48. Yusoff MSB, Mat Pa MN, Esa AR, Abdul Rahim AR: Mental health of medical students before and during medical education: A prospective study. J Taibah Univ Med Sci 2013, 8(2):86-92.

49. Alansari BM: Gender differences in depression among undergraduates from seventeen Islamic countries. Soc Behav Pers 2006, 34(6):729-738.

doi:10.1186/1472-6920-14-192

Cite this article as: AlFaris et al:: Student centered curricular elements are associated with a healthier educational environment and lower depressive symptoms in medical students. BMC Medical Education 2014 14:192.

\section{Submit your next manuscript to BioMed Central and take full advantage of:}

- Convenient online submission

- Thorough peer review

- No space constraints or color figure charges

- Immediate publication on acceptance

- Inclusion in PubMed, CAS, Scopus and Google Scholar

- Research which is freely available for redistribution

Submit your manuscript at www.biomedcentral.com/submit
C Biomed Central 